UCRL-JC-131920

PREPRINT

\title{
Effect of Angle-Ply Orientation on Compression Strength of Composite Laminates
}

\author{
Christopher P.R. Hoppel
}

Steven J. De Teresa

This paper was prepared for submittal to the 15th U.S. Army Symposium on Solid Mechanics

Myrtle Beach, SC

April 12-14, 1999

March 1999

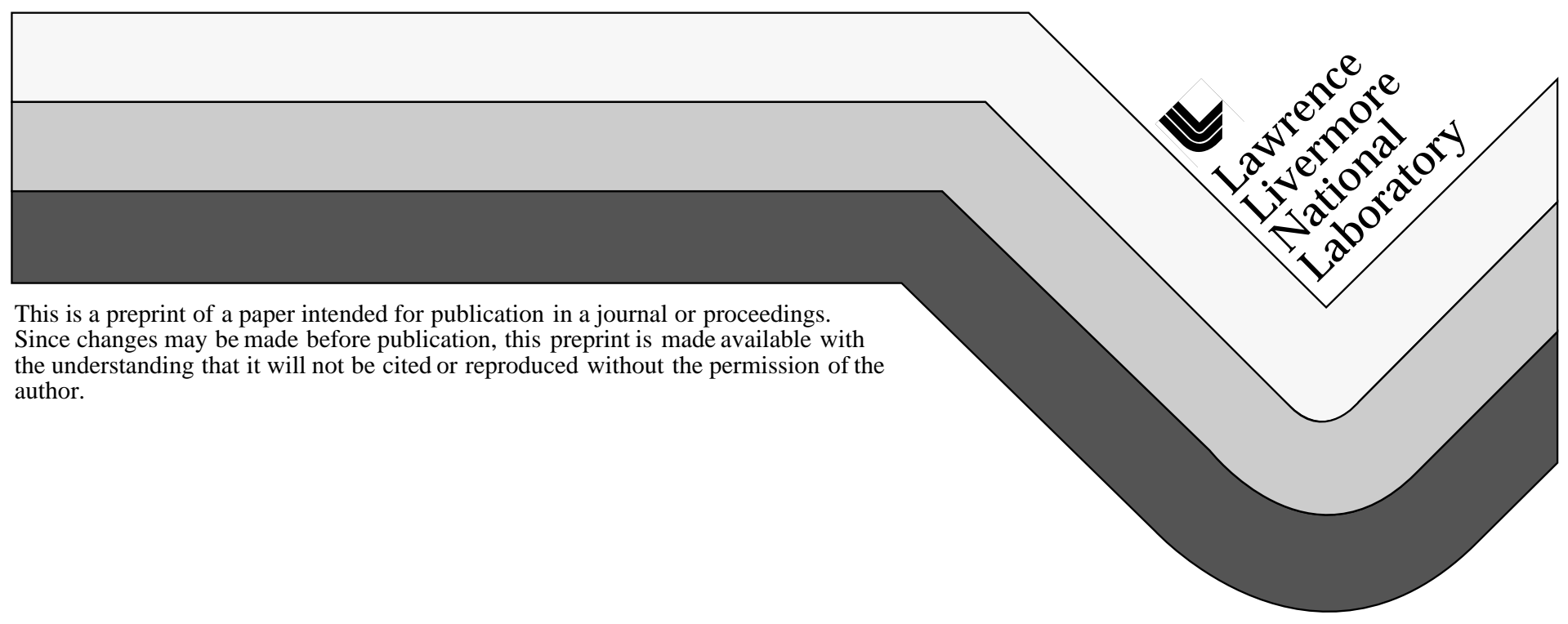




\section{DISCLAIMER}

This document was prepared as an account of work sponsored by an agency of the United States Government. Neither the United States Government nor the University of California nor any of their employees, makes any warranty, express or implied, or assumes any legal liability or responsibility for the accuracy, completeness, or usefulness of any information, apparatus, product, or process

disclosed, or represents that its use would not infringe privately owned rights. Reference herein to any specific commercial product, process, or service by trade name, trademark, manufacturer, or otherwise, does not necessarily constitute or imply its endorsement, recommendation, or favoring by the United States Government or the University of California. The views and opinions of authors expressed herein do not necessarily state or reflect those of the United States Government or the University of California, and shall not be used for advertising or product endorsement purposes. 


\title{
Effect of Angle-Ply Orientation on Compression Strength of Composite Laminates
}

\author{
Christopher P. R. Hoppel ${ }^{1}$ \\ Steven J. De Teresa ${ }^{2}$
}

\begin{abstract}
An experimental program was initiated to investigate the effect of angle-ply orientations on the compressive strength $\left(\mathrm{X}_{1 \mathrm{C}}\right)$ of $0^{\circ}$ plies in fiber reinforced composite laminates. Graphite fiber-reinforced epoxy test coupons with the generic architecture $\left[0_{2} / \pm \theta\right]$ (where $\theta$ varied between $0^{\circ}$ and $90^{\circ}$ ) and for the quasi-isotropic architecture were evaluated. The effective compressive strength of the $0^{\circ}$ plies varied considerably. The results were related to the Poisson's ratios of the laminates with high Poisson's ratios leading to high transverse tensile strains in the test coupons and lower than expected strengths. Specimens with the $\left[0_{2} / \pm 30\right]$ architecture had both the highest Poisson's ratio and the lowest calculated ply-level compression strength for the $0^{\circ}$ plies.

This work has implications in the selection of composite failure criterion for compression performance, design of test coupons for acceptance testing, and the selection of laminate architectures for optimum combinations of compressive and shear behavior. Two commonly used composite failure criteria, the maximum stress and the Tsai-Wu, predict significantly different laminate strengths depending on the Poisson's ratio of the laminate. This implies that the biaxial stress state in the laminate needs to be carefully considered before backing out unidirectional properties.
\end{abstract}

\section{Introduction}

Angle-ply or axially biased composite laminates are an important class of laminates because they combine good properties in the axial and shear directions. The Army has been interested in these laminates for a variety of ballistic applications. However, the $[30 / 0 /-30 / 0]_{2 S}$ architecture, which offered one of the best combinations of axial and shear properties, had a much lower experimental compressive strength than that predicted using the maximum stress or maximum strain failure criteria. The present investigation was

\footnotetext{
${ }^{1}$ U.S. Army Research Laboratory, AMSRL-WM-MB, Aberdeen Proving Ground, MD 21005; Phone: 410306-0859; e-mail: choppel@arl.mil

${ }^{2}$ Lawrence Livermore National Laboratory, 7000 East Avenue, MS L-342, Livermore, CA 94550; Phone: 925-422-6466; e-mail: deteresa1@1lnl.gov
} 
initiated to evaluate the cause of this low compressive strength and to evaluate the suitability of several failure criteria for predicting laminate compressive strength.

Compression testing of composite laminates is important for establishing failure limits as well as material quality control. However, compression test results can vary significantly depending on the test method and the architecture of the laminate being tested (Camponeschi 1991). In general, unidirectional laminates give low compressive strengths due to instability during failure. There has been significant interest (Camponeschi and Hoyns 1991; Wilson et al. 1994; Welsh and Adams 1996; Welsh and Adams 1997) in testing angleply or cross-ply composite laminates and "backing-out" the unidirectional strength of the material. The use of the back-out factor to calculate unidirectional strength assumes that the compressive failure is controlled solely by the axial stress in the $0^{\circ} \mathrm{ply}$.

Several investigators have evaluated the use of angle-ply laminates to determine $0^{\circ}$ compressive strength. Anquez (1994) proposed the biaxial stress state in the composite laminates as being important for evaluating compressive strengths. That work also proposed that optimum strength values could be obtained by backing out the $0^{\circ}$ strength from a $\left[0_{2} / \pm 60\right]$ laminate, which has the same Poisson's Ratio as a unidirectional laminate. Welsh and Adams (1997) reached a similar conclusion after evaluating angle ply laminates to obtain compressive strength.

In the present study, the effect of material architecture on the compressive strength is evaluated. Experimental results are given for a range of angle-ply laminates and the backed-out unidirectional strengths are discussed in light of the biaxial stress state within the composite laminates. The IM7/8551-7 graphite fiber reinforced epoxy material system is used for this evaluation. This material is of interest because it is used in a variety of Army applications including high performance projectiles and launch systems.

\section{Analysis}

A variety of failure criteria exist for composite materials (Nahas 1986). Some of the most common are the Maximum Stress, the Maximum Strain, and the Tsai-Wu (Tsai and $\mathrm{Wu}$ 1971). Of these, the maximum stress failure criterion does not account for any interaction between the stresses in the laminate but does identify the operative failure modes in the laminate. The maximum strain failure criterion provides some interaction between the stresses (due to Poisson's effects) and also identifies the operative failure modes. The Tsai$\mathrm{Wu}$ or tensor-polynomial criterion provides interaction between the stresses in the laminate but does not identify the specific failure mode. The Tsai-Wu equation is given in Equation 1 and the coefficients $F_{\mathrm{ij}}$ are listed in Equations 2 through 7. Two other failure criteria, proposed by Hashin (1980) and Christensen (1988), differentiate between fiber and matrix failure modes. For the fiber-dominate failure mode, both of these failure criteria are similar to the maximum strain criterion. 


$$
\begin{gathered}
F_{1} \sigma_{1}+F_{2}\left(\sigma_{2}+\sigma_{3}\right)+F_{11} \sigma_{1}^{2}+F_{22}\left(\sigma_{2}^{2}+\sigma_{3}^{2}\right)+2 F_{12} \sigma_{1}\left(\sigma_{2}+\sigma_{3}\right)+ \\
2 F_{23} \sigma_{2} \sigma_{3}+F_{44} \sigma_{4}^{2}+F_{66}\left(\sigma_{5}^{2}+\sigma_{6}^{2}\right)=1 \\
F_{1}=\frac{1}{X_{1 T}}-\frac{1}{X_{1 C}} \\
F_{2}=\frac{1}{X_{2 T}}-\frac{1}{X_{2 C}} \\
F_{11}=\frac{1}{\left(X_{1 T}\right)\left(X_{1 C}\right)} \\
F_{22}=\frac{1}{\left(X_{2 T}\right)\left(X_{2 C}\right)} \\
F_{44}=2\left(F_{22}-F_{23}\right) \\
F_{66}=\frac{1}{S_{6}^{2}}
\end{gathered}
$$

Jiang and Tennyson (1989) evaluated the elastic constants and failure allowables for the IM7/8551-7 material system in the principal directions. The results of their work are listed in Table 1 and Table 2. For the Tsai-Wu failure criterion, Hahn and Kallas (1992) determined the two interaction terms from biaxial testing: $F_{12}$, was reported as $4.001 * 10^{-11}$ $\mathrm{ksi}^{-2}\left(8.412 * 10^{-7} \mathrm{MPa}^{-2}\right)$ and $\mathrm{F}_{23}$, was reported as $6.1698 * 10^{-10} \mathrm{ksi}^{-2}\left(1.2972 * 10^{-5} \mathrm{MPa}^{-2}\right)$.

Table 1. Lamina Elastic Constants for IM7/8551-7 (Jiang and Tennyson 1989)

\begin{tabular}{|ccc|}
\hline Elastic Property & $\begin{array}{c}\text { Value } \\
\text { (English Units) }\end{array}$ & $\begin{array}{c}\text { Value } \\
\text { (Metric Units) }\end{array}$ \\
\hline $\mathrm{E}_{11}$ & $23.5 \mathrm{Msi}$ & $162 \mathrm{GPa}$ \\
$\mathrm{E}_{22}$ & $1.21 \mathrm{Msi}$ & $8.34 \mathrm{GPa}$ \\
$\mathrm{G}_{12}$ & $0.69 \mathrm{Msi}$ & $4.79 \mathrm{GPa}$ \\
$\mathrm{v}_{12}$ & 0.339 & 0.339 \\
\hline
\end{tabular}


Table 2. Lamina Failure Constants for IM7/8551-7 (Jiang and Tennyson 1989)

\begin{tabular}{|ccc|}
\hline Direction & $\begin{array}{c}\text { Strength } \\
(\mathrm{ksi})\end{array}$ & $\begin{array}{c}\text { Strength } \\
(\mathrm{MPa})\end{array}$ \\
\hline $\mathrm{X}_{1 \mathrm{~T}}$ & 351 & 2417 \\
$\mathrm{X}_{1 \mathrm{C}}$ & 150 & 1035 \\
$\mathrm{X}_{2 \mathrm{~T}}$ & 11 & 73 \\
$\mathrm{X}_{2 \mathrm{C}}$ & 26 & 176 \\
$\mathrm{~S}_{12}$ & 27 & 183 \\
\hline
\end{tabular}

Using the different failure criteria and the data reported by Jiang and Tennyson (1989) and Hahn and Kallas (1992), the predicted strengths were calculated for a series of angle-ply laminates. The strengths were calculated using LAM3D software (Bogetti, Hoppel, and Drysdale 1995), which uses a "smearing-unsmearing" theory (Chou, Carleone, Hsu 1972) to calculate ply level stresses in a laminate and apply failure criterion to each ply. The laminates had the generic form $[\theta / 0 /-\theta / 0]_{2 S}$ with $\theta$ varying between $0^{\circ}$ and $90^{\circ}$ and for the quasi-isotropic architecture $[45 / 90 /-45 / 0]_{2 S}$. The predictions do not include thermal stresses due to manufacturing the laminate or edge effects in the test specimens. The results are shown in Figure 1. LAM3D was also used to calculate the laminate Poisson's ratios as well as the ply level stress states at failure.

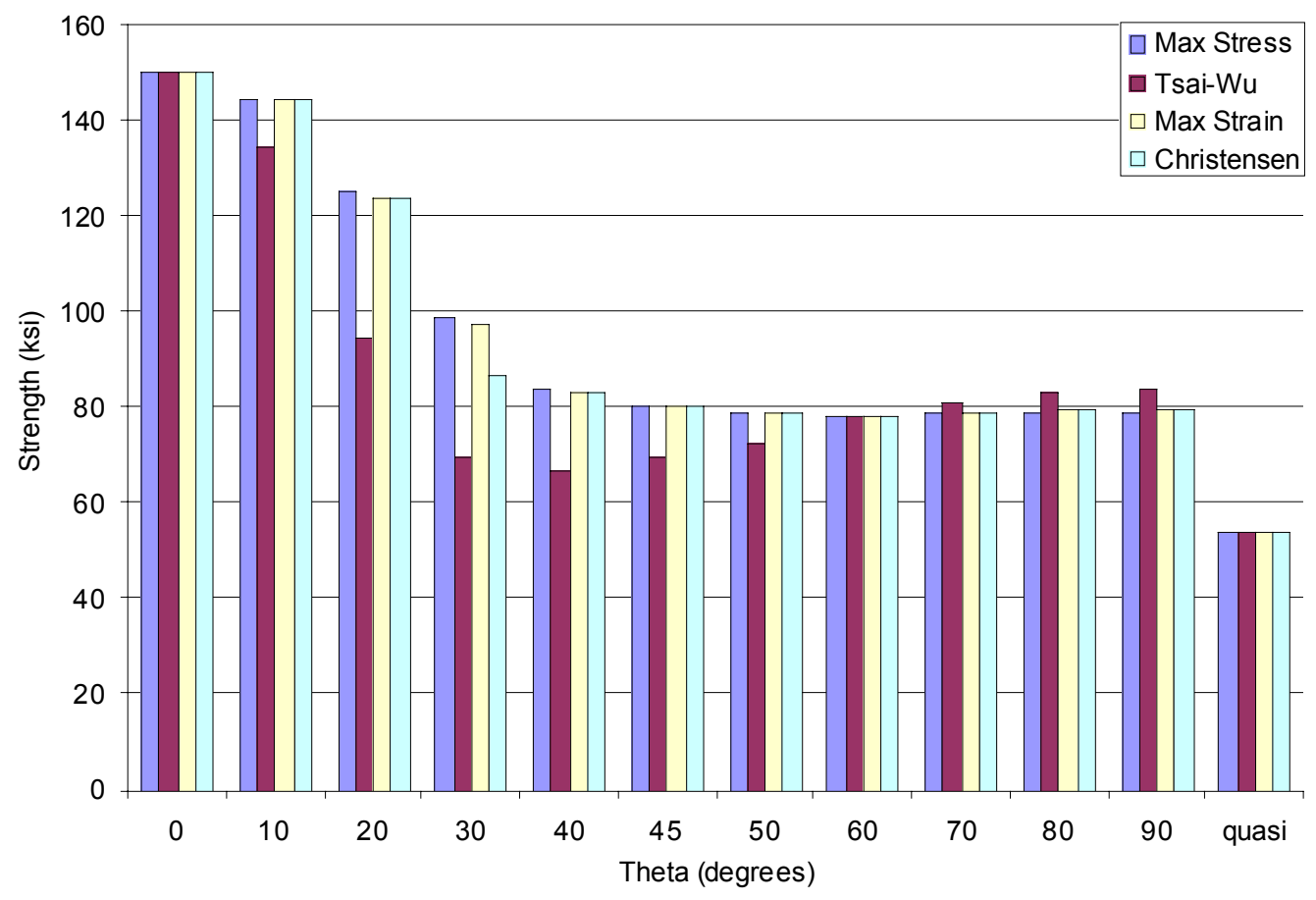

Figure 1. Effect of ply architecture on laminate strength for a series of laminates with the generic architecture $[\theta / 0 /-\theta / 0]_{2 S}$ with $\theta$ varying between $0^{\circ}$ and $\mathbf{9 0}^{\circ}$ and for the quasi-isotropic architecture $[45 / 90 /-45 / 0]_{2 S}$. 
From Figure 1, the four failure criteria show similar strength predictions when $\theta$ equals $0^{\circ}$ or $60^{\circ}$ and for the quasi-isotropic architecture; however, for other values of $\theta$, the predictions differ significantly. The main reason for these differences is the biaxial stress state in the $0^{\circ}$ ply for each of the architectures.

The Poisson's ratios are shown in Figure 2. The $[60 / 0 /-60 / 0]_{2 S}$ and $[45 / 90 /-45 / 0]_{2 S}$ architectures both have Poisson's ratios close to that of the unidirectional laminate. For values of $\theta$ between $0^{\circ}$ and $60^{\circ}$, the Poisson's ratio is much greater than that of the unidirectional lamina; the maximum Poisson's ratio is for the $[30 / 0 /-30 / 0]_{2 S}$ architecture. When the Poisson's ratios are greater than those of the unidirectional laminate, the $0^{\circ}$ plies are placed in transverse tension when the laminate is loaded in compression. The transverse tensile stresses in the $0^{\circ}$ plies in the center of the laminate at failure (based on the maximum stress failure criterion) were calculated using LAM3D and are plotted in Figure 3. The $[30 / 0 /-30 / 0]_{2 S}$ laminate shows transverse tensile loads close to the maximum allowable (Table 2). The transverse stresses are compressive for values of $\theta$ greater than $60^{\circ}$. These compressive stresses may add stability to the laminate and delay the axial compressive failure.

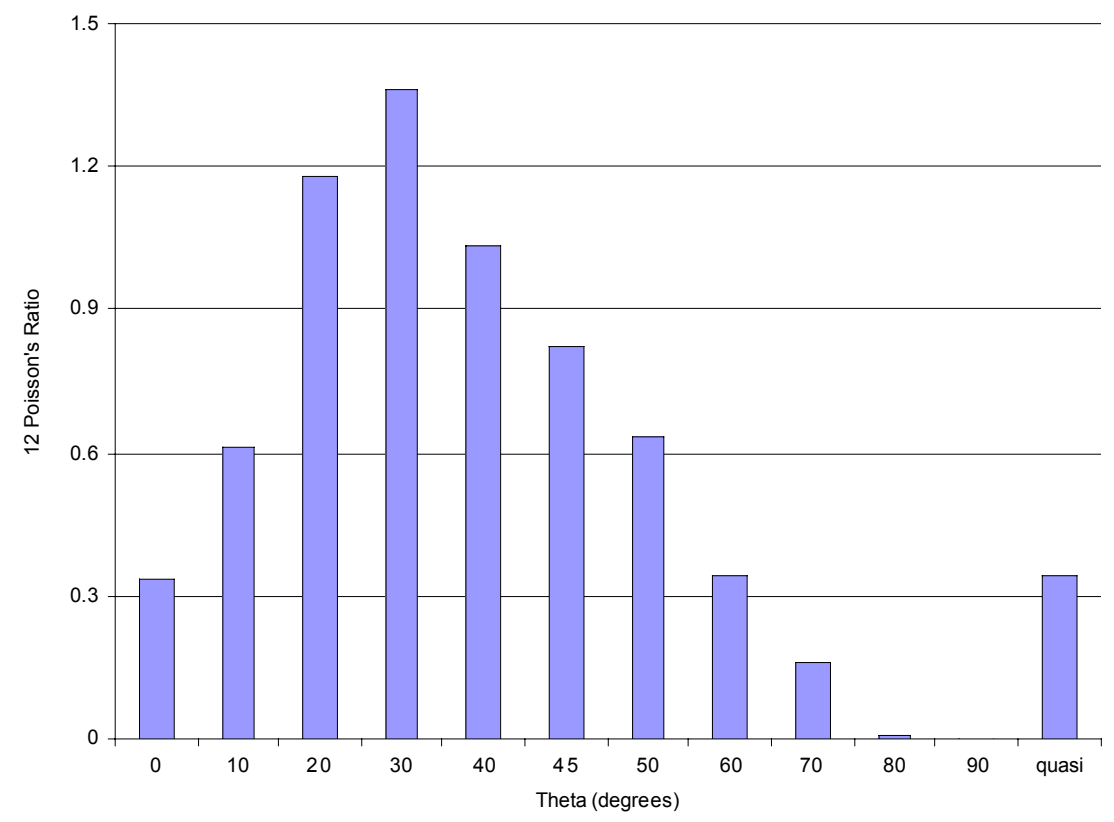

Figure 2. Effect of ply architecture on $v_{12}$ for a series of laminates with the generic architecture $[\theta / 0 /-\theta / 0]_{2 S}$ with $\theta$ varying between $0^{\circ}$ and $90^{\circ}$ and for the quasi-isotropic architecture $[45 / 90 /-45 / 0]_{2 S}$. 


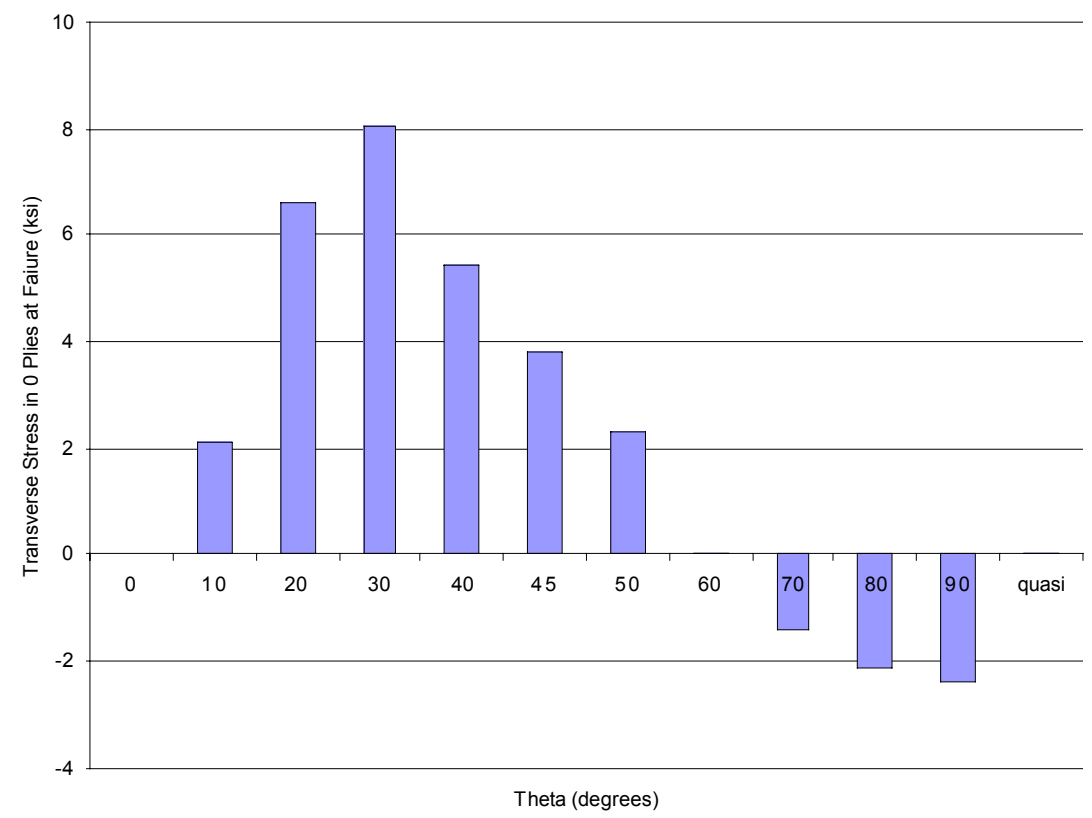

Figure 3. Transverse stresses in the $0^{\circ}$ ply at failure (based on the maximum stress failure criterion) for a series of laminates with the generic architecture $[\theta / 0 /-\theta / 0]_{2 S}$ with $\theta$ varying between $0^{\circ}$ and $90^{\circ}$ and for the quasi-isotropic architecture $[45 / 90 /-45 / 0]_{2 S}$. The transverse stresses are tensile for values of $\theta$ between $0^{\circ}$ and $60^{\circ}$, compressive for values of $\theta$ between $60^{\circ}$ and $\mathbf{9 0}^{\circ}$, and close to zero for the $0^{\circ},[60 / 0 /-60 / 0]_{2 S}$ and quasi-isotropic architectures.

The interactive failure criteria show significant effects due to the transverse stress state. The Tsai-Wu failure criterion predicts lower laminate strengths than the other failure criteria for laminates with high Poisson's ratios. For laminates with low Poisson's ratios, the Tsai-Wu criterion predicts higher strengths. The Maximum Strain and Christensen's failure criteria both predict laminate strengths similar to the Maximum Stress failure criterion, with the only exception being the prediction for the $[30 / 0 /-30 / 0]_{2 S}$ using Christensen's failure criteria. For this laminate, Christensen's criterion predicts a matrix dominated failure mode and a lower strength than the Maximum Stress or Maximum Strain.

\section{Experimental}

A series of laminates from the family $[\theta / 0 /-\theta / 0]_{2 S}$ with $\theta=0^{\circ}, 30^{\circ}, 45^{\circ}, 60^{\circ}$, and $90^{\circ}$ were made from IM7/8551-7 unidirectional prepreg. A laminate made from the widely used $[45 / 90 /-45 / 0]_{2 S}$ quasi-isotropic lay-up was also fabricated. Square 12" panels were autoclave cured following the manufacturer's recommended lay-up procedure and cure cycle. Cured panels were examined using ultrasonic C-scans and were found to be free of any gross porosity or delaminations. The average thickness of the cured ply was $0.0056^{\prime \prime}$. 
All compression tests were conducted using a variant of the Boeing-modified ASTM D695 specimen. These were $1 / 2^{\prime \prime}$ wide by $3.2^{\prime \prime}$ long strips of composite with either fiberglass or carbon fiber composite tabs adhesively bonded at each end to form a gage length of $0.4^{\prime \prime}$. Carbon fiber tabs were used for the unidirectional specimens after it was found that the weaker fiberglass would prematurely fail at the ends. The specimen is shown in Figure 4. It was selected because of its widespread use and compact size. Modifications to the standard specimen were made following the work by Haberle and Matthews (1994). Their work has shown that improved unidirectional strengths and reduced scatter are obtained when the high shear stresses near the tab end are relieved by eliminating the adhesive bond in this area. This unbonded area is made in a controlled manner by covering an area slightly greater than the gage section of the specimen with a release-coated tape prior to bonding the tabs. In the present study, the stress-relief preparation was used for both uni- and multidirectional laminates. For comparison, a set of unidirectional specimens was prepared without the release tape to give fully bonded tabs.

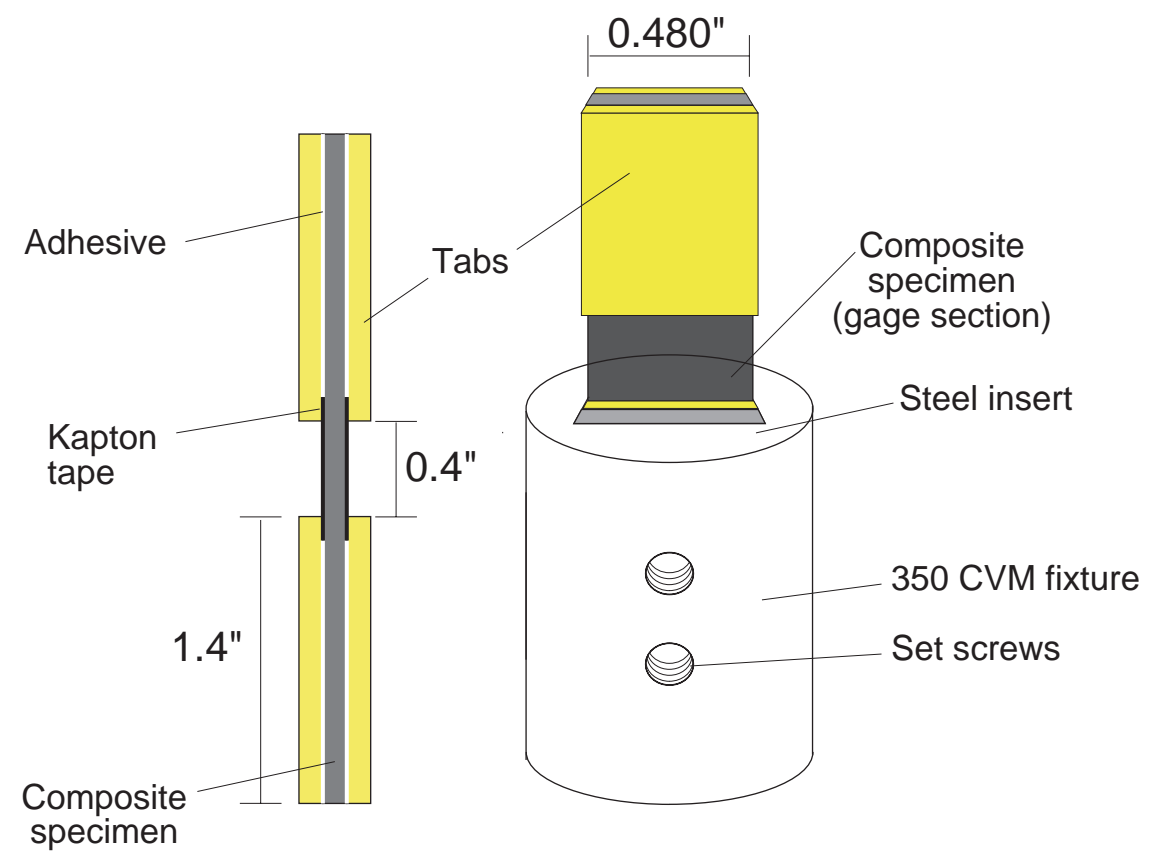

Figure 4. Schematic of tabbed compression specimen and fixture.

Specimens were prepared from 6" by 3.5" composite plates that were cut from the panels using a diamond saw under flood coolant. The gage area was covered with $3 / 4^{\prime \prime}$ wide Kapton tape that had a release backing. With this width tape, the final specimens have an intentional $0.18^{\prime \prime}$ unbonded length at the tab ends. The bonding surfaces were lightly abraded, then cleaned with acetone and isopropanol. Tabs 6" long by 1.5" wide were bonded to the composite using a 0.010" thick film adhesive (3M AF-126-2). An aluminum alignment fixture was used during the adhesive cure to maintain the position of the tabs. The adhesive was cured in a press under 50-psi pressure for one hour at $250^{\circ} \mathrm{F}$. Shims were used in the alignment fixture to yield an adhesive bondline that was nominally 0.005 " thick. 
All four edges of the tabbed panel were trimmed with the diamond saw using a previously marked panel edge for reference. The ends and the surfaces of the tabs were then ground flat and parallel also under flood coolant using a surface grinder. After grinding, the panel was sectioned into $0.5^{\prime \prime}$ wide specimens using the diamond saw and then ground to $0.480^{\prime \prime}$ widths using the surface grinder.

The compression test fixture shown schematically in Figure 4 is also based on some of the work due to Haberle and Matthews (1994). Like their design, ours utilizes two independent fixtures (only one is shown in the figure) and is thus free of any of the friction forces that are present in the standard D695 fixture. The ends of the specimen are fully contained in the fixture, which reduces the chance of end failures. It is designed for use in a high-pressure vessel for study of the effects of superimposed pressure on the failure of fiber composites. The two fixtures were machined from annealed $350 \mathrm{CVM}$ maraging steel with precision rectangular holes. The holes are $0.380^{\prime \prime}$ thick and $0.500^{\prime \prime}$ wide, which leaves room for lateral Poisson's expansion of the 0.480 " wide specimens. This expansion is significant in the \pm 30 and \pm 45 laminates and could lead to premature failure if constrained by the fixture. The thickness of the hole was designed to accommodate different tabbed specimens while leaving space for the steel insert as shown in the figure. A "grip" compression is applied to the tabs through the steel insert via two set screws on the side of the fixture. This force has been shown beneficial in preventing premature tab failures in compression tests (Haberle and Matthews 1994). Shims were used to center the $0.480^{\prime \prime}$ wide specimen in the $0.500^{\prime \prime}$ wide slots of the fixtures. These shims were left in place until after the set screws were tightened to a torque of $50 \mathrm{in}-\mathrm{lb}$. The alignment between the two fixtures is maintained by inserting the whole assembly inside a precisely bored guide tube. All tests were conducted at a stroke rate of $0.05 \mathrm{in} . / \mathrm{min}$ using an MTS servo-hydraulic test machine.

\section{Results}

The results of the laminate compression tests are listed in Table 3. Figure 5 gives some examples of failure in the \pm 60 , quasi-isotropic, and unidirectional laminates. The failure surfaces of most of the laminates were either a shear-type fracture oriented at about $70^{\circ}$ with respect to the load direction (the $0^{\circ}$ direction) or a brooming type failure. These fractures were confined to the gage section with many appearing to have occurred at one tab end. Both the stress-relieved and fully bonded unidirectional specimens also appeared to have failed at one end of the gage section. Despite this similarity, there was a noticeable improvement in strength for the specimens that were stress-relieved. This result is similar to the findings of Haberle and Matthews (1994). The average strength of the stress-relieved unidirectional specimen was $231 \mathrm{ksi}$. For comparison, manufacturer's data for this composite system claims a unidirectional compression strength in the range 243-252 ksi (Hercules Aerospace Products Group 1985), which is much higher than the result reported by Jiang and Tennyson (1989). 
In contrast, the \pm 30 laminates failed almost cleanly along one of the $30^{\circ}$ directions, leaving the fibers in the opposing $30^{\circ}$ plies and the $0^{\circ}$ plies completely severed. This indicates a different failure mode than the other specimens. Examples of this type of failure are shown in Figure 6. The failure propagated well into the tab area but appeared to have initiated in the gage section near the tab.

Table 3. Results of Laminate Compressive Tests and Backed-Out $0^{\circ}$ Strengths.

\begin{tabular}{|ccccc|}
\hline Laminate & $\begin{array}{c}\text { Average } \\
\text { Compressive } \\
\text { Strength } \\
(\mathrm{ksi})\end{array}$ & $\begin{array}{c}\text { Standard } \\
\text { Deviation }\end{array}$ & $\begin{array}{c}\text { Backed Out } 0^{\circ} \\
\text { Strength based on } \\
\text { Max Stress } \\
(\mathrm{ksi})\end{array}$ & $\begin{array}{c}\text { Backed Out } 0^{\circ} \\
\text { Strength based } \\
\text { on Tsai-Wu } \\
(\mathrm{ksi})\end{array}$ \\
\hline$[0]_{16}$ (no stress relief) & 211 & 3.3 & 211 & 211 \\
{$[0]_{16}($ stress relieved) } & 231 & 2.8 & 231 & 231 \\
{$[30 / 0 /-30 / 0]_{2 S}$} & 146 & 0.1 & 222 & 242 \\
{$[45 / 0 /-45 / 0]_{2 S}$} & 150 & 2.3 & 281 & 317 \\
{$[60 / 0 /-60 / 0]_{2 S}$} & 134 & 1.3 & 257 & 258 \\
{$[90 / 0]_{4 S}$} & 146 & 8.1 & 277 & 236 \\
{$[45 / 90 /-45 / 0]_{2 S}$} & 96 & 6.5 & 267 & 267 \\
\hline
\end{tabular}

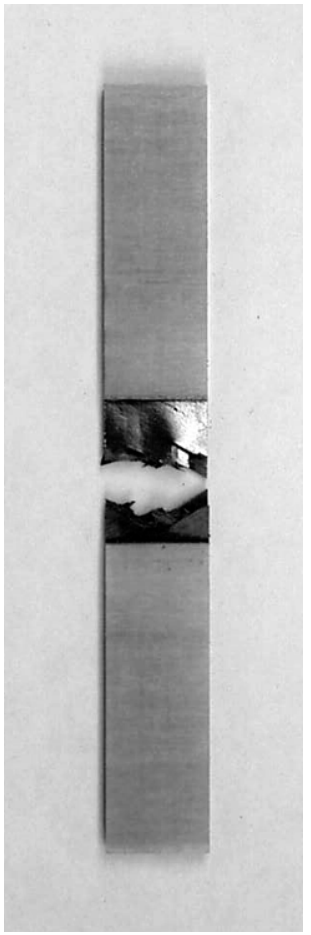

$[60 / 0 /-60 / 0]_{2 S}$

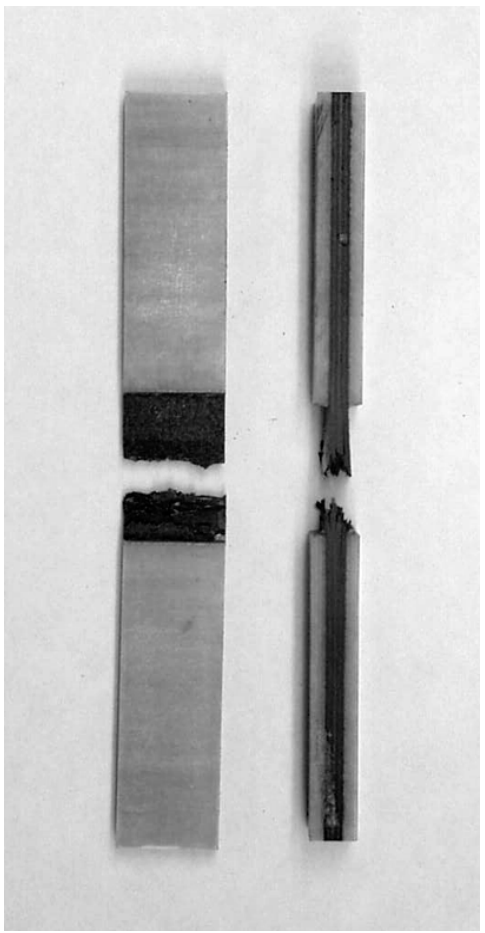

$[45 / 90 /-45 / 0]_{2 S}$
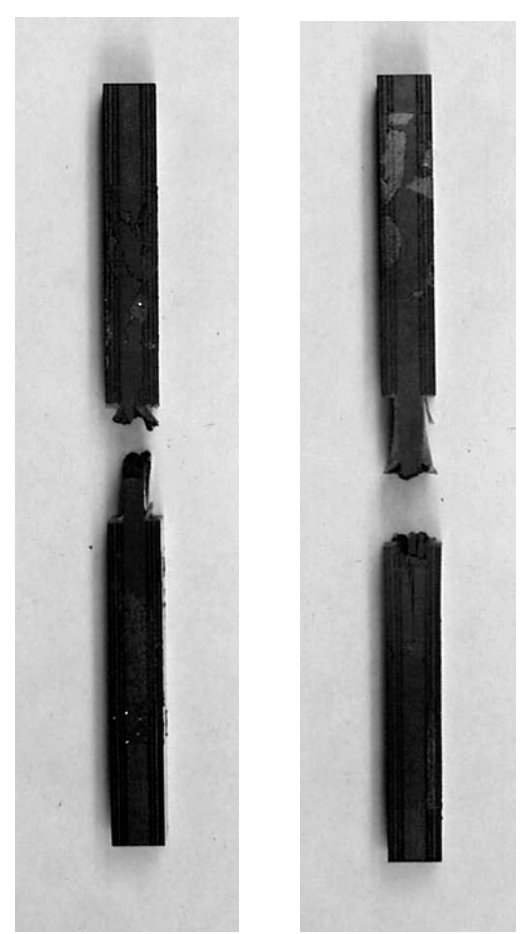

$[0]_{16}$ (Tape) $\quad[0]_{16}$ (No Tape) 
Figure 5. Failed specimens of \pm 60 , quasi-isotropic, and unidirectional laminates.

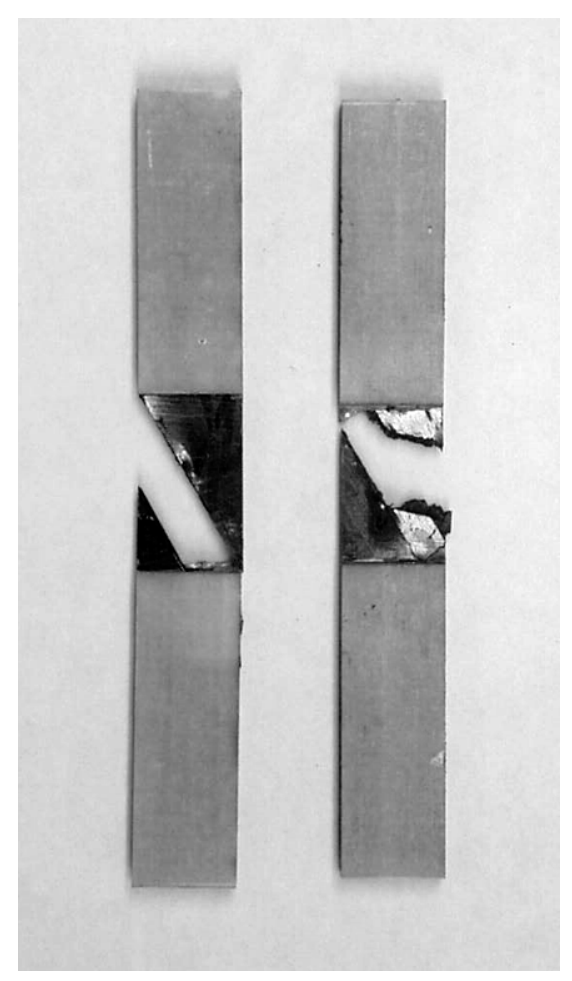

Figure 6. Failed specimens of $[30 / 0 /-30 / 0]_{2 S}$ laminates.

The $0^{\circ}$ strengths were backed-out of the experimental laminate strengths using two different methods. The maximum stress failure criterion method is the same as the back-out factor used in other studies (Camponeschi and Hoyns 1991). The backed Tsai-Wu strength was found by solving equations 1 through 7 for $\mathrm{X}_{1 \mathrm{C}}$ (the lamina compressive strength), assuming $\sigma_{3}=\sigma_{4}=\sigma_{5}=\sigma_{6}=0$ (this was true for all of the laminates evaluated in the present study based on analysis done with LAM3D software). The backed-out strengths are shown in Figure 7. The Tsai-Wu equation solved for $\mathrm{X}_{1 \mathrm{C}}$ is given in equation 8:

$$
\mathrm{X}_{1 \mathrm{C}}=\frac{\frac{\sigma_{1}^{2}}{X_{1 T}}-\sigma_{1}}{1-\frac{\sigma_{1}}{X_{1 T}}-\sigma_{2}\left(\frac{1}{X_{2 T}}-\frac{1}{X_{2 C}}\right)-\frac{\sigma_{2}^{2}}{\left(X_{2 T}\right)\left(X_{2 C}\right)}-2 \mathrm{~F}_{12} \sigma_{1} \sigma_{2}} .
$$




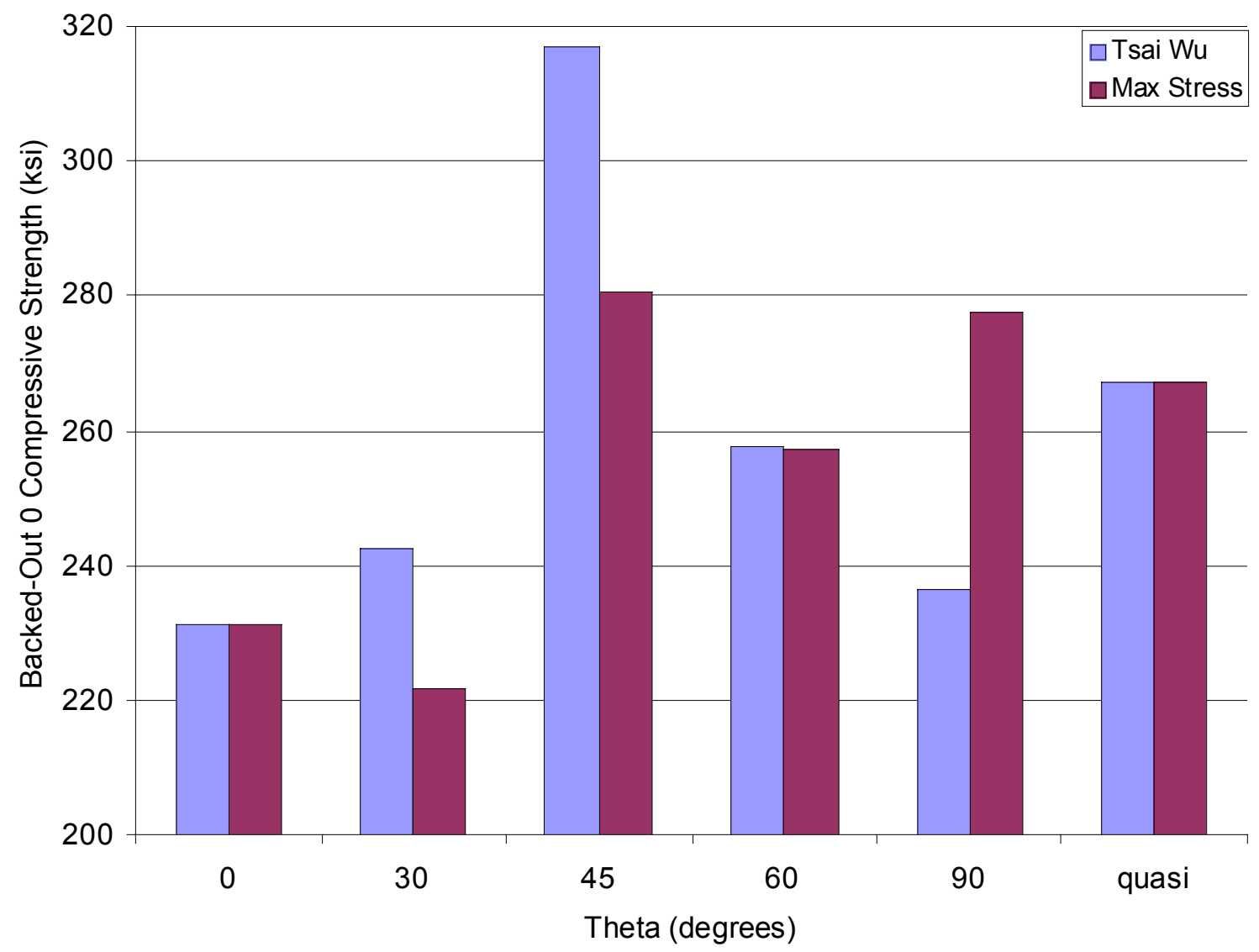

Figure 7. Backed-out compressive strengths for the $[\theta / 0 /-\theta / 0]_{2 S}$ and quasi-isotropic laminates.

\section{Discussion}

From the results in Table 3 and Figure 7, it can be seen that the backed-out unidirectional strengths for composite laminates can differ significantly depending on the laminate architecture as well as the method used to back out the strength. Using the Tsai-Wu failure criterion to back out the unidirectional strength, as was done here, is probably inappropriate for most applications because it assumes failure is dominated by the $0^{\circ}$ axial compressive strength. However, it was done in this paper to illustrate the importance of the biaxial stress state in the failure of the laminate. For angle-ply laminates with Poisson's ratios greater than the unidirectional lamina, the tensile transverse stresses in the $0^{\circ}$ plies may contribute to lower axial compressive strengths than in other architectures. Likewise, for cross-ply laminates, the compressive transverse stresses that develop in the $0^{\circ}$ plies may contribute to higher axial compressive strengths than in other architectures. In either case, backing out the unidirectional strength from these laminates using the maximum stress failure criterion ignores the biaxial stress state and can create misleading results. The laminates with the same Poisson's ratios as the unidirectional lamina (such as $[60 / 0 /-60 / 0]_{2 S}$ or $[45 / 90 /-45 / 0]_{2 S}$ ) 
remove the biaxial stress state and are more appropriate for backing out the unidirectional strengths. In the present analysis, these architectures gave the same backed out strengths for either maximum stress or Tsai-Wu back out factors.

It should be noted that all of the compressive strengths measured and calculated in this study were significantly higher than the $150 \mathrm{ksi}$ compressive strength originally reported by Jiang and Tennyson (1989) and used for the comparison in Figure 1. This demonstrates that differences in compressive test methods can also significantly affect strength predictions. The laminate compressive strengths were re-calculated using the 231 ksi unidirectional strength found in this study and the laminate strengths increased proportionally. One significant difference occurred; for the $[30 / 0-30 / 0]_{2 S}$ laminate with the $231 \mathrm{ksi}$ unidirectional axial strength, the maximum stress and maximum strain failure criteria predicted a transverse tensile failure mode, which is supported by the difference in failure mode seen in this study.

It should also be noted that the "backed-out" Tsai-Wu strengths calculated from equation 8 use the other failure constants from Jiang and Tennyson as listed in Table 2. Since these constants all have some variability, it adds to the total variability of the backed out Tsai-Wu strengths.

As discussed in the introduction, there are two main reasons for compression testing composite laminates: establishing failure limits and material quality control. The main focus of this paper has been the dangers associated with backing unidirectional strengths out of angle-ply laminates for establishing failure limits. While the authors do not recommend using a Tsai-Wu backed-out strength as was done here, it illustrates the importance of the biaxial stress state in compressive failure. This method of backing out unidirectional strengths may prove to be an effective method for comparing different failure criteria. The unidirectional strengths are considered constant input parameters for most lamina-based failure criteria. Therefore, a measure of the success of a particular criterion may be how consistent is the unidirectional strength that is calculated or backed-out for different laminates that fail by the same mode.

\section{Conclusions}

The influence of architecture on the compressive behavior of angle-ply composite laminates is evaluated. The analytic predictions and experimental results presented in this paper both show that the biaxial stress state that develops in angle-ply composite laminates has a significant effect on the axial compressive strength. Laminates with high Poisson's ratios, such as the $[30 / 0 /-30 / 0]_{2 S}$, produce transverse tensile strains when they are loaded in axial compression and consequently have lower strengths than predicted using a maximum stress type failure criterion. Similarly, laminates with low Poisson's ratio, such as the $[90 / 0]_{4 S}$, produce transverse compressive strains when they are loaded in compression and may give artificially high estimates of the unidirectional compressive strengths. 
This work has implications in the selection of composite failure criterion for compression performance, design of test coupons for acceptance testing, and the selection of laminate architectures for optimum combinations of compressive and shear behavior. Two commonly used composite failure criteria, the maximum stress and the Tsai- $\mathrm{Wu}$, predict significantly different lamina strengths depending on the Poisson's ratio of the laminate. Compressive strength is ultimately dependent on the materials, architecture, loading conditions, and structural geometry. At this point, the best way to evaluate the strength of composite structures is to test those structures in the architectures and loading state that they will experience. When this is not possible, the designer needs to acknowledge the uncertainties in the backed-out stress and increase their factor of safety accordingly.

\section{Acknowledgement}

S. J. DeTeresa gratefully acknowledges the support by the Joint DOE/DoD Technology Development Munitions Program and by the Office of Naval Research under Contract No. N00014-96-F-0422, technical monitor Dr. Y. Rajapakse. We also would like to thank Mr. Will Andrade and Mr. Jeff Petersen for their help with the design and machining of test specimens and hardware. 


\section{References}

Bogetti T. A., C. P. R. Hoppel, and B. P. Burns. "LAMPAT: A Software Tool for Analyzing and Designing Thick Laminated Composite Structures." ARL-TR-890, U.S. Army Research Laboratory, Aberdeen Proving Ground, MD, September 1995.

Bogetti T. A., C. P. R. Hoppel, and W. H. Drysdale. "Three-Dimensional Effective Property and Strength Prediction of Thick Laminated Composite Media." ARL-TR-911, U.S. Army Research Laboratory, Aberdeen Proving Ground, MD, October 1995.

Camponeschi Jr., E. T. "Compression of Composite Materials: A Review." Composite Materials: Fatigue and Fracture (Third Volume). ASTM STP 1110, T.K. O'Brien, Ed., American Society for Testing and Materials, Philadelphia, 1991, pp. 550-578.

Camponeschi Jr., E. T. and D. Hoyns. "Determination of Effective [0] Properties From [0/90] Laminate Testing." ASTM D30.04 Spring 1991 Meeting. American Society for Testing and Materials, Philadelphia, PA, 1991.

Chou, P.C., J. Carleone, and C. M. Hsu. "Elastic Constants of Layered Media." Journal of Composite Materials, vol. 6, pp. 80-93, 1972.

Christensen, R.M. "Tensor Transformation s and Failure Criteria for the Analysis fo Fiber Composite Materials.” Journal of Composite Materials, vol. 22, pp. 874-897, 1988.

Feng, W.W. "A Failure Criterion for Composite Materials." Journal of Composite Materials, vol. 25, pp. 88-100, 1991.

Haberle, J.G. and Matthews, F.L., "An Improved Technique for Compression Testing of Unidirectional Fibre-Reinforced Plastics; Development and Results," Composites, vol 25, no. 5, 358-371, 1994.

Hahn, H.T., and M. N. Kallas. "Failure Criteria for Thick Composites." BRL-CR-691, U.S. Army Ballistic Research Laboratory, Aberdeen Proving Ground, MD, June 1992.

Hoppel C. P. R., T. A. Bogetti, and J. W. Gillespie Jr. "Effects of Hydrostatic Pressure on the Mechanical Behavior of Composite Materials." ARL-TR-727, U.S. Army Research Laboratory, Aberdeen Proving Ground, MD, April 1995.

Hashin, Z. "Failure Criteria for Unidirectional Fiber Composites." Journal of Applied Mechanics. Vol. 47, pp. 329-334, 1980.

Magnamite ${ }^{\circledR}$ 8551-7 Tough Resin, Graphite Prepreg Tape and Fabric Summary, Hercules Aerospace Products Group, Bacchus Works, Magna, UT, November (1985) and Product Data Sheet.

Nahas, M.N. "Survey of Failure and Post-Failure Theories of Laminated Fiber-Reinforced Composites." Journal of Composites Technology and Research, vol. 8, pp. 138-153, 1986. 
Tsai, S. W., and E. M. Wu. "A General Theory of Strength for Anisotropic Materials." Journal of Composite Materials, vol. 5, pp. 58-80, 1971.

Tsai, S.W. Composites Design, Forth Edition. Think Composites, Dayton, Ohio, 1987.

Welsh, J.S. and D.F. Adams, "Unidirectional Composite Compression Strengths Obtained by Testing Cross-Ply Laminates." Journal of Composites Technology \& Research. vol. 18, no. 4, pp. 241-248, 1996.

Welsh, J.S. and D.F. Adams, "Testing of Angle-Ply Laminates to Obtain Unidirectional Composite Compression Strengths." Composites Part A. vol. 28A, pp. 387-396, 1997.

Wilson, D.W., V. Altstadt, M. Maier, J. Prandy, K. Thoma, and D. Vinckier. "An Analytical and Experimental Evaluation of 0/90 Laminate Tests for Compression Characterization." Journal of Composites Technology \& Research. vol. 16, no. 2, pp. 146-153, 1994. 